\title{
Improving the Quality of Training and Service in Obstetrics and gynecology Practice in Developing Countries -Sudan as a sample
}

\author{
Abdelatif Ashmaig* and Mohammed Abdelmoneim \\ President of the Obstetrics \& Gynecology Society of the Sudan, President of the National Ribat University, President of the Ian DONALD \\ SCHOOL-SUDAN BRANCH, Sudan \\ *Corresponding author: Abdelatif Ashmaig, MGO, DDUS, FRCOG, IAPM, President of The Ob. \& Gyn. Society of the Sudan, \\ President of the National Ribat University, President of the Ian DONALD SCHOOL-SUDAN BRANCH, Sudan
}

\begin{tabular}{|c|c|}
\hline ARTICLE INFO & ABSTRACT \\
\hline Received: 㓞 June 03, 2019 & Citation: Abdelatif Ashmaig, Mohammed Abdelmoneim. Improving the Quality of Train- \\
\hline Published: 幽 June 10, 2019 & $\begin{array}{l}\text { ing and Service in Obstetrics and gynecology Practice in Developing Countries -Sudan as } \\
\text { a sample. Biomed J Sci \& Tech Res 18(4)-2019. BJSTR. MS.ID.003194. }\end{array}$ \\
\hline
\end{tabular}

\section{Contents}
a) Learning objectives.
b) Introduction.
c) Improvements at Community level.
d) Improvement at health care facility level, including the health care provider.
e) Improvement at Government level.
f) Take home massage.

Learning objectives
a) Importance to keep improving the quality of training \& care.
b) The vital role of Midwives [MW] and Community Health Workers [CHW].
c) Importance of "Task shifting".

\section{Introduction}

a) It is essential that we keep improving the quality of training, as this will have a profound impact on all aspects:

i. The health care provider, the patient and the health care facility.

b) There are many levels where improvement can continuously be applied:
i. The community levels.
ii. Health care facility level, including the health care provider.
iii. Government level.

\section{Improvements at Community Level}

\section{Starts at the "Patient" or Family Level, that is by:}
a) Improving the awareness of different health issues.
b) Should also include training and support of the Midwives [MW] and the community health workers [CHW].
c) They should be targeted as they are likely to be the first line to which the Obs /gyne cases present.
d) Can also include "Task shifting".

\section{Support Should be at the:}

a) Financial to the family, MW \& CHW.

b) Financial for the local health facility [improving the working environment]

c) By providing MW, CHW \& local health facilities with the materials they need to provide the service [for example: vaccinations, contraception, pregnancy vitamins, simple leaflets, surgical instruments,]. 
d) By delivering basic training programs [basic practical skills, basic life support, neonatal resuscitation, sterilization \& disinfection, manual vacuum aspiration,].

e) by making it easier to reach the health facility.

f) A well trained community MW will be able to manage the common obstetric and gynecological presentations including caring for pregnant women, managing normal deliveries, referring high risk pregnancies and complicated deliveries on time, giving breastfeeding advice, providing contraception.

g) A well trained CHW can-for example- give sexual health advice, preconception advice and participate in vaccination programs.

\section{Task Shifting}

a) The dramatic shortage of physicians, nurses, pharmacists, and other clinicians and health personnel makes traditional models of healthcare delivery (eg, physician-centered) an unrealistic option in many settings.

b) In response to this crisis, task shifting has been increasingly promoted and studied as one strategy to address this major global health problem.

c) The World Health Organization (WHO) described task shifting as the rational redistribution of tasks among health workforce teams.

d) When feasible, healthcare tasks are shifted from highertrained health workers to less highly trained health workers in order to maximize the efficient use of health workforce resources.

\section{Improvement at the health care facility and provider level:}

a) Many aspects can be addressed here, including training programs for the doctors, referral systems,

b) Improvement of the infrastructures \& improving the working environment.

c) Solutions must be implemented to:

i. Simplify the often-unnecessary complexity of delivering medical care.

ii. Create systems and tools that minimize errors and catch those that do occur before they can cause harm.

\section{Task shifting can also be Implemented here}

Henry M. Lerner, MD has described eight tools developed over time by clinicians who have worked in the field of obstetric patient safety. These tools provide some answers and concrete starting points:

i. Continuing education

ii. Simulation training

iii. Audits

iv. Best-practice protocols

v. Safety checklists

vi. Complete documentation, including prepared templates

vii. Smart medical records

viii. Outside review of maternity unit characteristics and performance

\section{Improvement at the Governmental Level}

a) Many aspects can be addressed here, for instance:

i. Increasing the fund directed for the health system.

ii. Giving support for the operational researches like the Maternal mortality reports and national audits.

b) The role of the Government?!

i. Improving the communication means and to strengthen the referral system

\section{Take Home Massage}

a) Improving the quality of training and service in Obstetrics and gynecology practice starts at the community level [the patient and family, the midwife, the community health worker], goes through the higher levels of health care providers [doctors, nurses, 2ndry level health care facilities] \& escalates to reach the government level.

b) Midwifes and community health workers can play vital role in improving the quality of care provided.

c) Task shifting, where responsibilities and tasks can be shifted from higher trained health workers to less highly trained health workers in order to maximize the efficient use of health workforce resources, needs to be appropriately addressed. 
ISSN: 2574-1241

DOI: 10.26717/BJSTR.2019.18.003194

Abdelatif Ashmaig. Biomed J Sci \& Tech Res

(C) This work is licensed under Creative

Submission Link: https://biomedres.us/submit-manuscript.php

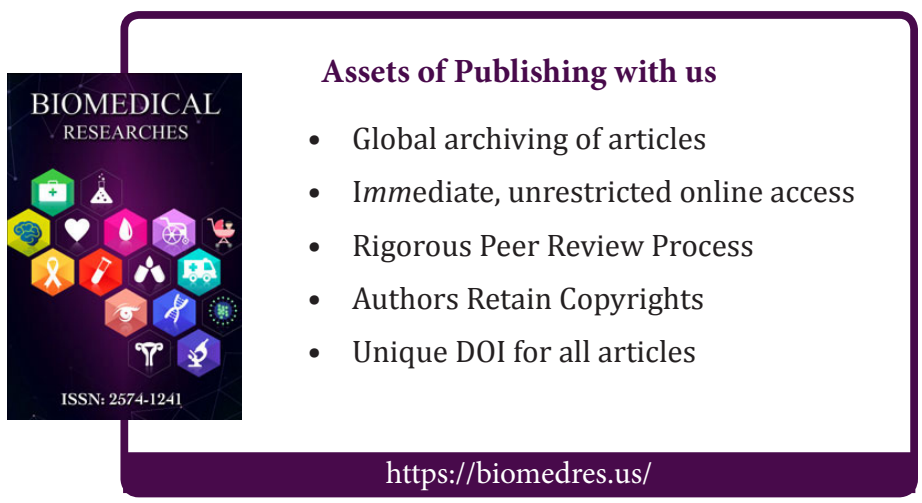

